\title{
O SÍSIFO DA FLORESTA NOS BRAÇOS DO MAPINGUARI: DIÁLOGOS ENTRE EUCLIDES DA CUNHA E FLORENTINA ESTEVES \\ Luis Fernando Ribeiro ALMEIDA ${ }^{1}$ \\ José Guilherme de Oliveira CASTRO ${ }^{2}$
}

\begin{abstract}
RESUMO
Este artigo tem por objetivo fazer um estudo comparativo entre o texto "Mapinguari", de Florentina Esteves e "Um clima caluniado", de Euclides da Cunha, a fim de identificar os possíveis pontos de confluências discursivas. Este estudo está baseado em levantamento bibliográfico, utilizando-se dos postulados da Literatura Comparada e do conceito de dialogismo de Bakhtin. É possível observar a presença da figura do seringueiro nos textos analisados, verificando-se assim, que tanto no texto de Florentina Esteves, quanto no de Euclides da Cunha, embora remotos no tempo, tomam o mesmo espaço como pano de fundo de suas narrativas: a floresta, que se mostra gigantesca, "engolindo" o homem, "carregando-o" nos braços, revelando sua pequenez diante da "prisão celular".
\end{abstract}

Palavras-chave: Literatura. Dialogismo. Amazônia. Imaginário.

\begin{abstract}
This article aims to make a comparative study between the text "Mapinguari" by Florentina Esteves and "A climate slandered", by Euclides da Cunha, in order to identify the possible points of discursive confluences. This is based on a bibliographical survey, using the postulates of Comparative Literature and Bakhtin's concept of dialogism. It is possible to observe the presence of the figure of the rubber latex gatherer in the texts analyzed, thus verifying that both Florentina Esteves and Euclides da Cunha's text, although remote in time, take the same space as the background of their narratives: The forest, which shows itself to be gigantic, "swallowing" the man, "carrying him" in his arms, revealing his littleness before the "cell prison".
\end{abstract}

Keywords: Literature. Dialogism. Amazon. Imaginary.

1 Mestrando do Programa de Pós-Graduação em Comunicação, Linguagens e Cultura (PPGCLC) da Universidade da Amazônia (UNAMA). Membro do Grupo de Pesquisa Interfaces do Texto Amazônico - GITA/UNAMA. E-mail fernandoalmeida15@yahoo. com.br.

2 Doutor em Letras pela Pontifícia Universidade Católica do Rio Grande do Sul. É professor titular da Universidade da Amazônia (Unama), do- cente efetivo do Programa de Pós-Graduação em Comunicação, Linguagens e Cultura. Líder do Grupo de Pesquisa Interfaces do Texto Amazônico - GITA/UNAMA E-mail: VOL. $14 \mid$ N. 1 | JUN. 2017 zevone@superig.com.br. 


\section{PREÂMBULO}

3 Escritor fluminense (18661909). Autor da obra "Os Sertões", texto inaugural do Pré-Modernismo no Brasil.

4 Aspecto mais evidente em seu texto Solidariedade Sul-Americana, puclicado originalmente em O País (RJ, 31 de março de 1904).

5 Guerra de Canudos ocorrida em 1897 no norte da Bahia. Euclides da Cunha fora enviado para cobrir os momentos finais do combate pelo então jornal O Estado de São Paulo.

6 Euclides da Cunha é nomeado em agosto de 1904, pelo então Ministro das Relações Exteriores, o Barão do Rio Branco, como cheje da Comissão de Reconhecimento do Alto Purus, no objetivo de fazer o levantamento cartográfico da região, partindo da foz às cabeceiras do rio Purus, a fim de ajudar nas demarcações de limites entre Brasil e Peru.

7 Obra organizada por Euclides da Cunha e publicada postumamente em setembro de 1909. Dividida em quatro partes: Terra sem história (Amazônia); Vários estudos; Da Independência à República e Estrelas indecifráveis.

8 Escritora e Membro da Academia Acreana de Letras, cadeira no $^{\circ} 4$.

Este artigo faz parte de uma profícua jornada pelos textos amazônicos do escritor fluminense Euclides da Cunha ${ }^{3}$, caminhada que remonta os idos de 2009 , quando do contatato com os primeiros escritos de temática amazônica do autor. Obras como À margem da história (1909), precisamente a sua primeira parte: Terra sem história (Amazônia) e alguns textos contidos em Contrastes e Confrontos (1907), apresentam como temáticas recorrentes as peculiaridades da floresta imensa; da exploração dos seringueiros; além dos ideais euclidianos de integração da região ao progresso: trazer a Amazônia para seu aspecto de protagonista do gigantismo do Brasil $^{4}$

Para a produção deste artigo, em especial, a atenção recai sobre uma figura muito presente nos textos amazônicos do autor: o seringueiro. Assim como tivera a oportunidade de conhecer a face do sertanejo em Canudos $^{5}$, pode-se dizer que Euclides da Cunha, em sua passagem ${ }^{6}$ pela região Norte do país, mais precisamente pelo território acreano, deparou-se com outro drama humano: a condição de exploração a qual eram submetidos os seringueiros: sertanejos em outra "vestimenta".

Dentre as duas obras mencionadas, aquela que contém escritos com descrições mais detalhadas sobre o seringueiro é À margem da história ${ }^{7}$, sendo escolhido para este debate o ensaio Um clima caluniado. No que respeita a importância do referido texto, nele encontra-se uma das associações que Euclides da Cunha faz do seringueiro: compara-o à figura mitológica de Sísifo; aspecto que será aprofundado posteriormente neste estudo.

$\mathrm{Na}$ tentativa de trazer à baila as "letras verdes" euclidianas, revelando sua atualidade, sobretudo referente às questões de integração e preservação da Amazônia, bem como o registro atencioso à vida do seringueiro e sua condição de "preso" na floresta, busca-se com este debate, relacionar a escrita euclidiana com a literatura produzida pela escritora acreana Florentina Esteves, uma vez que a autora retoma a questão da floresta e do seringueiro como componentes importantes de suas narrativas, o que pode ser observado no conto Mapinguari.

Percorrendo os caminhos da Literatura Comparada, no que diz respeito à aproximação de dois textos, a fim de detectar pontos de aproximação ou distanciamento, procura-se com este trabalho analisar a figura do seringueiro debatido no texto de Euclides da Cunha, bem como o presente no conto de Florentina Esteves. Nessa tarefa de aproximação textual, o conceito de dialogismo bakhtiniano será importante, uma vez que compreende o texto como o espaço de diálogo, quer seja entre interlocutores quer entre discursos.

Para o bom desenvolvimento deste estudo, de início é proposto o debate do conceito de dialogismo em Bakhtin, ressaltando sua relevância para os estudos que se debruçam sobre o texto literário, pautando-se no entendimento de que o texto é o campo de cruzamento de muitas vozes que estão em diálogo. Em seguida, debate-se a relação de Euclides da Cunha com os seringueiros, suas impressões e discurso de denúncia. Nesse campo, abre-se um item destinado à análise do ensaio Um clima caluniado, dando relevo à passagem em que o autor associa a figura do seringueiro ao mitológico Sísifo.

Dando continuidade, faz-se a análise do conto Mapinguari, de Florentina Esteves ${ }^{8}$, acentuando seu caráter imagético e simbólico, uma vez que a escritora contrói sua narrativa a partir de um mito indígena muito difundido na região amazônica e que povoa a imaginação dos que ali habitam em especial a população da floresta, inserido nesse contexto o seringueiro na sua rotina de trabalho. Resguardadas as primeiras análises dos textos utilizados como corpus para este estudo, destina-se o último item para debater os pontos de confluências entre aqueles, evocando-se a figura do seringueiro-sertanejo e sua relação com a floresta em toda sua miríade de mitos e lendas. 


\section{O DIALOGISMO BAKHTINIANO}

Os postulados bakhtinianos deram um novo ordenamento às tradicionais análises literárias já tão marcadas pelo Estruturalismo ${ }^{9}$ e Formalismo ${ }^{10}$ e que, ao longo de décadas, serviram de suporte para muitos estudiosos. Muito desse ordenamento deu-se em decorrência da forma de se entender o texto e suas características peculiares. Ao compreender o texto como uma unidade de sentido e que por isso traz em si um significado, ou melhor, significações, analisá-lo de maneira isolada de fatores externos a ele interferentes, é reduzir as possibiliades de interpretações.

Dentre os muitos conceitos formulados por Bakhtin, um parece servir de eixo orientador para o tipo de análise aqui proposta, é o dialogismo. O primeiro ponto que merece destaque é o entendimento de que a obra literária não tem seu fim no momento em que é publicada, pois pensar assim seria deixar para segundo plano o leitor enquanto produtor de sentidos, resumindo o autor e seu texto como únicos protagonistas do processo de interação verbal. Nessa perspectiva, o texto outrora ciscunscrito ao escritório ou a sala de trabalho, bem como subordinado à escrita desde ou daquele autor, no ato de sua publicação, torna-se um objeto que, por sua natureza, passa a ser matéria de interpretação para aqueles que o leem ${ }^{11}$.

O segundo aspecto relacionado a esse tipo de texto, é o seu valor figurativo. Diz-se figurativo o texto em que predomina a conotação, ou seja, o emprego das palavaras fora do sentido usual, genérico, a partir do uso de recursos expressivos como metáfora, comparação, antítese, metonímia, dentre outros que conferem ao texto um caráter estético e por isso mesmo passível de diferentes interprertações. Feitas essas duas ponderações em relação ao texto literário, passa-se doravante ao debate da ideia de dialogismo.

De início, o conceito de dialogismo parte da ideia de diálogo. Tomando-se diálogo como forma de interação entre sujeitos, é coerente entender quando Bakhtin defende a ideia de que o texto, enquanto criação de sujeitos em interação, também congrega diálogos que podem ser entre interlocutores ou entre discursos, fundamentando-se "na negação da possibilidade de conhecer o sujeito fora do discurso que ele produz, já que só pode ser apreendido como uma propriedade de vozes que ele anuncia" (DAHLET, 2005, p. 58).

Para os debates aqui iniciados, a partir deste momento, o foco destina-se ao segundo aspecto do dialogismo bakhtiniano: o diálogo entre discursos. Embora remotos no tempo, tanto o texto de Euclides da Cunha quanto o de Florentina Esteves aproximam-se quanto ao espaço da narrativa: a floresta/seringal e um personagem em comum: o seringueiro. Pode-se então, verificar uma correspondência temática nos dois escritos, em Mapinguari, da escritora acreana, temos a personagem Artêncio Pereira, seringueiro, nordestino que tem a visão do "monstro"; já em Um clima caluniado tem-se a "gênese" da saga sertaneja em direção aos seringais amazônicos. É possível, ao ler o texto de Florentina Esteves, verificar pontos que se interligam com o que foi produzido por Euclides da Cunha. Em Bakhtin tem-se, portanto o entendimento “" [...] do texto literário como um 'mosaico', construção caleidoscópica e polifônica, estimulou a reflexão sobre a produção do texto, como ele se constrói, como absorve o que escuta". (CARVALHAL, 2003, p. 48-49)

Essa caracteística dialogal entre discursos/textos pode ser assim sistematizada: “[...] define o texto como um 'tecido de muitas vozes' ou de muitos textos ou discursos, que se entrecuzam, se completam, respondem umas às outras ou polemizam entre si no interior do texto." (BARROS, 2005, p.33). Nessa perspectiva, evidencia-se o aspecto dialógico da linguagem, portanto o diálogo é condição da linguagem e do discurso.

\section{EUCLIDES DA CUNHA E O SERINGUEIRO}

O contexto em que Euclides da Cunha vivenciou/experimentou a Amazônia deu-se precisamente no decurso do ano de 1905. Este momento de nossa história
9 Relacionado aos postulados de Ferdinand de Saussure.

10 Formalismo Russo. Em seu caráter ortodoxo, toma o texto desvinculado de fatores externos à sua produção.

11 Para o Interacionismo Simbólico, de Herbert Blumer, o sujeito é um agente em sua relação com o mundo e com os objetos aos quais entra em contato, criando para si um universo de significações. 
mostra que a região conheceu um intenso desenvolvimento econômico, este, por sua vez, propiciado pela riqueza oriunda da comercialização da borracha. Esse produto de exportação favoreceu as cidades polos, principalmente Manaus e Belém, um alvorecer de construções luxuosas e o desenvolvimento fabril. A borracha produzida servia principalmente de matéria-prima para produtos automotivos, uma vez que o desenvolvimento desses meios de transporte encontrava seu auge nos ditames do modelo fordista norte-americano de produção. Segundo Fausto (2008):

A Amazônia viveu um sonho transitório de riqueza graças à borracha. O avanço da produção que vinha ocorrendo em décadas anteriores tomou grande impulso a partir de 1880. A verdadeira mania pela bicicleta, nos anos 1890, e a gradativa popularização do automóvel, a partir da virada do século, incentivaram ainda mais a produção. Em toda a época de seu apogeu, a borracha ocupou folgadamente o segundo lugar entre os produtos brasileiros de exportação, alcançando o ponto máximo entre 1898 e 1910. (FAUSTO, 2008, p. 291).

É importante destacar que apesar de toda riqueza gerada pela produção da borracha, a população das classes menos assistidas economicamente desses centros econômicos ainda encontrava-se em condições insalubres de vida. Enquanto os barões da borracha e a alta classe inebriavam-se no espírito da Belle Époque amazônica nos rituais da civilização "visando também à manutenção ou ao reforço do prestígio da sua elite, que se colocava à altura de seus parceiros nos grandes negócios da borracha" (DAOU, 2004, p.56), no interior desse processo econômico, encontravam-se os seringueiros, inseridos em um trabalho árduo no interior da floresta, e foi em favor desse indivíduo que Euclides da Cunha dedicou algumas páginas em À margem da história.

Toda essa "corrida da borracha" favoreceu um "inchaço" populacional produzindo uma classe excluída de toda e qualquer assistência governamental. Em relação a essa questão, Fausto (2008) ao referir-se ao ciclo da borracha, aponta: "Calcula-se que entre 1890 a 1900 a migração líquida para a região - ou seja, a diferença entre os que entraram e saíram - foi de cerca de 110 mil pessoas. Elas provinham, sobretudo do Ceará, um Estado periodicamente batido pela seca". (FAUSTO, 2008, p. 291). Ora, será que Euclides da Cunha estaria de fato abalado com aquela população que chegava aos montes à Amazônia? A questão que ressoa em seus escritos parece ser justamente essa. Mas, que gente era essa que ali chegava? E quem os trazia? Para isso o próprio escritor aponta no ensaio Um clima caluniado:

De fato - à parte o favorável deslocamento paralelo ao Equador, demandando as mesmas latitudes - não se conhece na História exemplo mais golpeante de emigração tão anárquica, tão precipitada e tão violadora dos mais vulgares preceitos de aclimamento, quanto o da que desde 1879 até hoje atirou em sucessivas levas, as populações sertanejas do território entre a Paraíba e o Ceará para aquele recanto da Amazônia [...] Tem um reverso tormentoso que ninguém ignora: as secas periódicas dos nossos sertões do Norte, ocasionando o êxodo em massa das multidões flageladas [...] Mandavam-nos para a Amazônia - vastíssima, despovoada, quase ignota - o que equivalia a expatriá-los dentro da própria pátria [...] Mas feita a tarefa expurgatória, não se curava mais dela. Cessava a intervenção governamental. Nunca até, aos nossos dias, acompanhou um só agente oficial, ou um médico. (CUNHA, 2000, p. 149-150).

Nessa passagem, o autor deixa transparecer que talvez o ideal republicano do qual foi defensor dos mais fervorosos, não estaria cumprindo com os ideais pro- 
postos com sua criação, um país próspero e democrático. Mas o que vale ressaltar é o posicionamento do escritor frente à situação encontrada. Visualiza-se a postura de um homem que não estava apenas preocupado em cumprir a missão a qual lhe fora confiada, mas sim, um homem de olhar atento às questões sociais.

Essa página singular que vemos nos escritos de Euclides da Cunha - o destaque para a situação dos seringueiros - revela que o escritor, como alguns estudiosos ainda acreditam, não era apenas uma pessoa que estava relatando fatos, mas imprime seu estilo de literato na composição textual, ultrapassando as impressões superficiais, chegando ao caráter profético, quer dizer, revelando problemas perceptíveis em pleno século XXI. Em relação à função do Estado republicano na construção de uma mão de obra para a extração do látex nos confins da Amazônia, destaca: "Para isto o colono, ou o emigrante, torna-se em toda a parte um pupilo do Estado. Todos os seus atos, desde o dia da partida [...] predeterminam-se em regulamentos rigorosos". (CUNHA, 2000, p. 148).

Lendo as passagens sobre os seringueiros e sabendo que elas advinham dos grandes sertões do Nordeste, emerge a célebre frase do escritor: "O sertanejo é, antes de tudo, um forte" (CUNHA, 2005, p. 146), assim referiu-se ao povo que encontrara em Canudos. Bem, esses mesmos indivíduos que o escritor retratou magistralmente nas páginas de Os sertões, o mesmo iria encontrar tempos depois embrenhados na imensidão da floresta amazônica, subjugados aos "mandos e desmandos" dos senhores da borracha. E, ao ver novamente esse ser humano que sai dos interiores dos sertões, arrasado pela seca, para a imensidão das águas, é que o autor escreve. Nessa busca de novos horizontes, esses sertanejos, como bem pondera Euclides da Cunha, ao adentrarem no novo cenário: "ali estacionam, cumprindo, sem o saberem, uma das maiores empresas destes tempos. Estão amansando o deserto". (CUNHA, 2000, p. 146).

\subsection{Um clima caluniado: a gênese da saga sertaneja aos seringais acreanos}

O texto Um clima caluniado ${ }^{12}$ é um importante ensaio que registra o processo de povoamento da região do Acre por nordestinos durante o ciclo da borracha. $\mathrm{Na}$ busca de justificar o título do texto, Euclides da Cunha oferece ao leitor três argumentos para "desmontar" a ideia de que o clima amazônico, tão criticado pelos viajantes, seria responsável por certo "atraso" da região, mas antes uma falta de adaptação do homem ao território. Por meio de uma linguagem própria de quem dominava a "pena" com singular cuidado, aponta os seguintes argumentos: o que se realizou na região foi uma "seleção telúrica"; não é o clima que é mau, é o homem; por fim, os indivíduos ali presentes "não são feitos do meio, surgem a despeito do meio".

Mas que um pretenso estudo de natureza climática, o texto euclidiano pode ser entendido como uma espécie de tratado antropológico, na medida em que descreve a origem da mão de obra utilizada nos seringais e seus dilemas homem x floresta, afirmando que os nordestinos cearenses e pernambucanos estavam ali "em uma das maiores empresas destes tempos" (CUNHA, 2000, p.146) e seriam amansadores de deserto - agora deserto verde.

Ainda em relação à presença desses sertanejos na região, afirma que esse processo de emigração aconteceu de forma anárquica, ou seja, de maneira desorganizada, confusa, caótica. Paralisados pelos longos processos de estiagem, os sertanejos eram agenciados, de certa forma iludidos, e enviados aos montes, sem nenhum conforto, para a então desconhecida floresta amazônica. Entretanto, a intervenção governamental cessava ao passo que esses trabalhadores chegavam aos seringais.

Chamados de "expatriados dentro da própria pátria" (CUNHA, 200, p.150) esses sertanejos passariam a cumprir exaustivas tarefas de extração do látex, sem qualquer auxílio ou perspectiva de volta à terra de origem. Dessa maneira, o autor apresenta a questão central do seringueiro, este seria "o homem que trabalha para escravizar-se" (CUNHA, 2000, p. 152): vítima da seca, iludido pela "fácil fortuna" e
12 Segundo notação na Obra completa de Euclides da Cunha (Nova Aguilar, 2009), sob organização de Paulo Roberto Pereira, Um clima caluniado teria sido publicado originalmente no Jornal do Commercio (RJ) em 20 de fevereiro de 1907. 
agora escravo da sua rotina na imensa floresta. Em relação ao trabalho desenvolvido pelos seringueiros, Euclides da Cunha constrói uma das passagens mais angustiantes do texto, quando compara o seringueiro à personagem mitológica Sísifo ${ }^{13}$ :

Dostoiévski sombrearia as suas páginas mais lúgubres com esta tortura: a do homem constrangido a calcar durante a vida inteira a mesma "estrada", de que ele é o único transeunte, trilha obscurecida, estreitíssima e circulante, ao mesmo ponto de partida. Nesta empresa de Sísifo a rolar em vez de um bloco o seu próprio corpo - partindo, chegando e partindo nas voltas constritoras de um círculo demoníaco, no seu eterno giro de encarcerado numa prisão sem muros, agravada por um oficio rudimentar que ele aprende em uma hora para exercê-lo toda a vida, automaticamente, por simples movimentos reflexos - se não o enrija uma sólida estrutura moral, vão-se-lhe, com a inteligência atrofiada, todas as esperanças, e as ilusões ingênuas, e a tonificante alacridade que o arrebataram àquele lance, à ventura, em busca da fortuna. (CUNHA, 2000, p. 153).

13 Segundo a mitologia grega, Sísifo seria o mais astuto dos homens e fundador da cidade de Corinto. Dentre suas astúcias, teria revelado para o deus-rio Asopo que Zeus havia raptado sua filha Egina. Como punição, Zeus ordenou que Tanatos, deus da morte, levasse o astuto monarca, todavia por uma engenhosa manobra, aprisiona o seu algoz e como consequência ninguém mais morria Enfurecido, Hades queixa-se a Zeus que ordena que Ares, deus da guerra, liberte Tanatos, sendo Sísifo levado para a morada de Hades. Através de outra engenhosidade, o rei de Corinto acaba voltando para o mundo dos vivos. No fim de sua vida, já com a idade avançada, morre e retorna ao Hades. Como punição por todas as suas trapaças, é condenado a rolar uma pesadíssima pedra morro acima, porém a pedra sempre caía, tendo Sísifo de recomeçar seu trabalho, eternamente.
Observando-se atentamente essa passagem do texto euclidiano, fica latente certo sentimento íntimo de um homem preocupado com o social. Poder-se-ia até destacar a presença de um Euclides da Cunha com um apuramento estético igual ou até mais aguçado que o de Os sertões. Associando o espaço amazônico como uma espécie de ergástulo: "É a conservação sistemática do deserto, e a prisão celular do homem na amplitude desafogada da terra" (CUNHA, 2000, p. 154) coloca em evidência a figura do seringueiro como aquele que, na condição de cativo, exerce todos os dias a mesmas tarefas no seringal, sendo estas aprendidas logo que da chegada à "nova morada".

Nota-se nessa passagem, um recurso muito comum na escrita euclidiana: as expressões associativas/comparativas/metafóricas: referência à determinada figura mitológica; um aspectos da natureza ou menção à alguma personagem literária. Precisamente em Um clima caluniado, Euclides da Cunha compara o seringueiro com a figura mitológica de Sísifo. A própria narrativa mitológica desse personagem é carregada de simbolismos. Pela tradição, Sísifo é considerado o grande enganador, aquele que por sua esperteza conseguiu ludibriar os deuses. Todavia, como aspecto comum nessas narrativas, todo aquele que por algum motivo ofendera os deuses, deveria ser castigado, ou seja, punido. Nesse aspecto, a tradição oferece muitos casos: Aracne, que por ousar ser superior à deusa Atena fora transformada em uma aranha; Prometeu, que por roubar o fogo sagrado dos deuses e entregá-lo aos homens, sofrera o castigo de ter sido acorrentado em um penhasco, tendo por algoz uma ave que devorava todos os dias seu fígado; Calisto, jovem que provocou o ciúme de Juno, que a transformou numa ursa e Actéon, que por um lance de momento teria visto a deusa Diana, sendo por ela transformado em uma espécie de cervo.

Tendo por punição carregar pela eternidade uma gigantesca pedra morro acima, Sísifo é tido como símbolo do trabalho inútil, uma vez que o rochedo sempre caía, tendo o coríntio que recomeçar seu eterno ofício, voltando sempre ao ponto de partida. Segundo a tradição:

[...] o astuto rei foi condenado a rolar penosamente com a ajuda dos ombros e das mãos, um enorme rochedo até o cume de uma abrupta montanha. Quando estava prestes a alcança-lo, o rochedo tornava a cair sozinho na planície e Sísifo devia, e para a eternidade, recomeçar o inútil trabalho. (MEUNIER, 1961, p. 149)

É precisamente nesse aspecto que o seringueiro, recorrente nos escritos

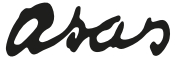
VOL. 14 | N.1 | JUN. 2017 euclidianos, representaria a imagem desse personagem mitológico, que como bem 
destaca Euclides da Cunha, estaria preso na floresta amazônica, interpretado como um castigo resultado de um desejo de enriquecimento utópico que o fizera deixar o Nordeste e seguir rumo à Amazônia. Tendo que aprender um novo ofício, agora extrair o látex da seringueira, em uma forma de trabalho repetitivo, solitário, cansativo, rolando seu corpo como a pedra do astuto rei de Corinto, sempre indo e voltando pelas mesmas estradas ${ }^{14}$. O seringueiro poderia ser interpretado como o Sísifo da floresta, manietado ${ }^{15}$ à sua própria condição de trabalho. Nesse ensaio, Euclides da Cunha recorre à mitologia para reforçar um aspecto social: o trabalho do seringueiro. Ao fazer uso desse dispositivo, o escritor fluminense dialoga com Campbell (1990) que considera que o mito ajuda a colocar a mente do leitor em contato com a experiência de estar vivo.

Ao findar o texto, Euclides da Cunha volta à questão inicial se sua reflexão sobre o clima, concluindo, por meio de um enunciado que desmistifica a insalubridade do mesmo, que seria o clima responsável por preparar a natureza para os mais fortes, que perseveram e são bondosos.

\section{LITERATURA E IMAGINÁRIO AMAZÔNICO: O MAPINGUARI, DE FLORESTINA FERNANDES}

Mapinguari é o sexto texto do total de trinta e dois que compõem o livro Direito e Avesso da acreana Florentina Esteves, obra que reúne uma série de narrativas que gravitam pelo universo dos rios, seringais, florestas, barracões, bem como aspectos periféricos da vida no ambiente urbano. Trata-se de uma narrativa aos moldes do gênero conto: enredo sintético, poucas ações e personagens, além de uma história bem delimitada no tempo e no espaço. Apropriando-se do imaginário popular do povo amazônico e suas narrativas míticas, principalmente em relação aos seres encantados da floresta, a autora conta, por meio de um narrador em terceira pessoa, o encontro da personagem Artêncio Pereira, seringueiro da região do Acre, com o Mapinguari ${ }^{16}$. Em relação ao imaginário amazônico:

Na Amazônia as pessoas ainda veem seus deuses, convivem com seus mitos, personificam suas ideias e as coisas que admiram. A vida social ainda permanece impregnada do espírito da infância, no sentido de encantar-se com a explicação poetizada e alegórica das coisas. Procuram explicar o que não conhecem, descobrindo o mundo pelo estranhamento, alimentando o desejo de conhecer e desvendar o sentido das coisas em seu redor. (LOUREIRO, 1995, p. 103).

Tomando como mote esse encontro "assombroso", a autora fornece ao leitor, por meio da narrativa literária, elementos que caracterizam a vida e os hábitos dos seringueiros, na figura de Artêncio: seu trabalho exaustivo nos seringais e seus dilemas com a imensidão da floresta, tão vasta e misteriosa. Interessante perceber que o espaço da floresta entra no conto como um componente simbólico:

Nas concepções religiosas e nas crenças populares de inúmeros povos, [a floresta] desempenha um papel significativo como área sagrada e misteriosa, habitada por deuses bons e maus, por espíritos e demônios, por homens selvagens, por entidades femininas ligadas à madeira, ao musgo e à floresta, por fadas etc. [...] Por essa razão, representações de florestas ou a floresta na qualidade de cenário de ações dramáticas muitas vezes referem-se simbolicamente ao irracional [...] (LEXIKON, 1994, p. 98).
14 Caminho formado pelo conjunto de 100 seringueiras.

15 De mãos atadas, algemado, preso. Alguém privado de liberdade.

16 Pela tradição dos povos nativos, o Mapinguari seria um ser de dimensões gigantescas, de pelo avermelhado, com um único olho, a exemplo da figura mitológica de Ciclope e que exala um cheiro horrível. Seria uma espécie de protetor da floresta contra os caçadores, sendo chamado de "comedor de homens". 
rador apresenta as atividades do seringueiro e sua organização, tomando como exemplo a tarefa de defumar a borracha ${ }^{17}$ : "Dobrou cuidadosamente a estopa, colocou-a num cantinho, a seus pés, junto com a espingarda, o terçado e o cansaço daquele longo dia. Lançou mais um olhar desconfiado para a boca do varadouro, deu um suspiro fundo, e foi defumar borracha”. (ESTEVES, 1998, p. 17). Através de uma linguagem bem próxima do interlocutor, a escritora acreana convida o leitor a entrar no universo do imaginário amazônico, ou pelo menos em uma parcela dele, contribuindo de maneira para o fomento das produções que tomam o espaço amazônico como fio condutor da narrativa.

\section{O SÍSIFO DA FLORESTA NOS BRAÇOS DO MAPINGUARI}

A tarefa de um escritor talvez seja a mais desgastante das artes. Certa vez em entrevista, a romancista Rachel de Queiroz, ao ser perguntada sobre o ofício do escritor, respondera que escrever seria como um parto, algo sofrido e ao mesmo tempo recompensador. No que respeita à Literatura, esta que, em uma definição bem elementar, é entendida como a "arte da palavra", parece que a função do autor seja dar vida, ou seja, forma às diferentes histórias oriundas de sua relação com o mundo e com os outros, encarnando na escolha vocabular a essência do "ser".

Poder-se-ia dizer que a literatura navega em torno de quatro grandes temas: amor, sofrimento, vida e morte, ladeados pela figuração, simbolismos e discursos. Essas construções literárias acabam em algum momento dialogando ${ }^{18}$ entre si, podendo ser na mesma época ou de maneira remota. Um exemplo desses diálogos é o caso que apresento neste artigo entre o texto Mapinguari da escritora acreana Florentina Esteves e Um clima caluniado, do escritor fluminense Euclides da Cunha. Produzidos em épocas diferentes, ambos trazem a temática do seringueiro para o centro do debate e da criação estética, um pelos caminhos do conto, outro pelos horizontes do ensaio.

No texto de Florentina Esteves, tem-se um conto que dialoga com o imaginário amazônico. Valendo-se do mito do Mapinguari, a escritora constrói uma narrativa tendo como personagem principal o seringueiro Artêncio Pereira, que em dado momento do texto, acaba defrontando-se com um "ser monstruoso", sendo por este carregado em seu momento de inconsciência:

De repente ele viu o Mapinguari à sua frente. Grande - altura de uma árvore - peludo, um olho só, que olhava para ele. Artêncio quis encolher-se, sumir, o corpo não obedecia, rígido. E o bicho continuava a olhá-lo, quieto. Depois, devagarinho, estendeu as duas mãos peludas e levantou Artêncio como se levanta uma criança. Levo-o à altura da boca, e Artêncio viu que sua garganta parecia a boca de um enorme forno quente, de onde vinha um bafo fedorento. Quis soltar-se, o corpo petrificado não parecia ser seu corpo. (ESTEVES, 1998, p. 18).

17 O processo de defumação consistia no aquecimento da borracha, fazendo-a coagular formando uma pele endurecida.

18 Referência ao dialogismo bakhtiniano.

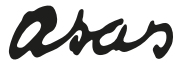

Observando as marcas linguísticas presentes na tessitura da narrativa da escritora acreana, ao dar voz à personagem, o narrador acaba por revelar a origem do mesmo, este seria, um nordestino, notadamente identificado pela expressão "Que isso, Artêncio Pereira, tu é cabra-macho ou não?” (ESTEVES, 1998, p. 17), além de nos parágrafos seguintes, ser evidenciada a questão da religiosidade, outra característica dos moradores do sertão brasileiro: "Melhor rezar, encomendar a alma a Deus". (ESTEVES, 1998, p. 18).

Euclides da Cunha em sua passagem pela região amazônica em 1905 e consequentemente nos textos produzidos a partir dessa sua experiência enfatiza que os seringueiros da região do Acre, eram, em sua maioria, nordestinos vindos do Ceará e Pernambuco. Essa origem pode ser verificada nos fragmentos extraídos de Um clima caluniado, em que temos a descrição do processo de migração dos nordestinos para 
a região amazônica e o papel do Estado nessa "empreitada", além de comparar o seringueiro-sertanejo com Sísifo, que no lugar de uma pedra, rolava seu próprio corpo na imensa floresta, a partir de atividades repetitivas.

Esse aspecto do trabalho repetitivo também pode ser observado no texto de Florentina Esteves, o seringueiro indo e voltando ao mesmo ponto de partida: "Todo dia era a mesma coisa: saía pra cortar, com escuro. Percorria um tanto de estradas, a metade do caminho talvez, e aí começava a cisma". (ESTEVES, 1998, p. 17). Enfim, pode-se perceber que tanto no texto de Florentina Esteves, quanto no de Euclides da Cunha, embora remotos no tempo, tomam o mesmo espaço como pano de fundo para as narrativas: a floresta, em seu aspecto de gigantismo, que "engole" o homem, "amansa-o", carregando-o nos braços, revelando sua pequenez diante dos mistérios da natureza.

\section{CONSIDERAÇÕES}

Sendo o texto um espaço de diálogo, quer seja entre interlocutores, ou entre discursos, ao aproximar os textos de Euclides da Cunha com o de Florentina Esteves, verifica-se que em ambos há uma correspondência temática: o espaço da floresta com toda sua simbologia e o seringueiro em sua tarefa diária. Euclides da Cunha ao associar a figura do seringueiro com o personagem mitológico de Sísifo revela o drama desses trabalhadores oriundos do sertão nordestino, que levados por um desejo de fortuna, acabam tendo uma vida como um eterno castigo, presos à floresta em repetidas tarefas.

No que diz respeito ao conto de Florentina Esteves, fica latente a força da tradição popular, evidenciada pela presença da figura mitológica do Mapinguari, que povoa o imaginário dos habitantes da floresta, inserindo-se nesse contexto o seringueiro que passa a incorporar em seu discurso essa tradição oriunda dos indígenas; sendo, como é descrito na narrativa, carregado pelo lendário "comedor de homens". Em suma, quando se pondera já no título o Sísifo da floresta nos braços do Mapinguari, procurou-se, sobretudo revelar o cotidiano, os dramas e conflitos da vida do seringueiro: um homem que é envolvido pela floresta, a "prisão celular", espaço tão imenso, povoado de mitos e lendas que passam a influenciar em sua vida e nos seus costumes.

\section{REFERÊNCIAS}

BARROS, Diana Luz Pessoa de. Contribuições de Bakhtin às teorias do discurso. In: BRAIT, Beth (org). Bakhtin, dialogismo e construção do sentido. 2. ed. Campinas, São Paulo: Editora da UNICAMP, 2005.

CAMPBELL, Joseph. O poder do mito. Betty Sue Flowers (org). Tradução de Carlos Felipe Moisés. São Paulo: Palas Athena, 1990.

CARVALHAL, Tania Franco. Literatura Comparada. São Paulo: Ática, 2003.

CUNHA, Euclides da. Um clima caluniado. In:__._. .Um paraíso perdido: reunião de ensaios amazônicos. Seleção e coordenação de Hildon Rocha. Brasília: Senado Federal, Conselho Editorial, 2000. (Coleção Brasil 500 anos). p.145-157.

Os sertões. São Paulo: Martin Claret, 2005.

DAOU, Ana Maria. A Belle Époque amazônica. 3. ed. Rio de Janeiro: Jorge Zahar Ed, 2004. 
(org). Bakhtin, dialogismo e construção do sentido. 2. ed. Campinas, São Paulo: Editora da UNICAMP, 2005.

ESTEVES, Florentina. Mapinguari. In: Direito e avesso. Rio de Janeiro: Oficina do Livro, 1998.

FAUSTO, Boris. História do Brasil. 13. ed. São Paulo: Editora da Universidade de São Paulo, 2008. (Didática, 1).

LEXIKON, Herder. Dicionário de símbolos. 8. ed. São Paulo: Cultrix, 1994.

LOUREIRO, João de Jesus Paes. Cultura amazônica: uma poética do imaginário. Belém: Cejup, 1995.

MEUER, Mário. A legenda dourada: nova mitologia clássica. Tradução de Alcântara Silveira. São Paulo: IBRASA, 1961. Beth (org). Bakhtin, dialogismo e construção do sentido. 2. ed. Campinas, São Paulo: Editora da UNICAMP, 2005. 